\title{
ESTIMATIVA DO VENTO PARA OS BAIXOS NÍVEIS UTILIZANDO IMAGENS DOS CANAIS VISÍVEL E INFRAVERMELHO PRÓXIMO $3.9 \mu \mathrm{m}$
}

\author{
RENATO GALANTE NEGRI, LUIZ AUGUSTO TOLEDO MACHADO \\ Instituto Nacional de Pesquisas Espaciais - INPE \\ Centro de Previsão de Tempo e Estudos Climáticos/ \\ Divisão de Satélites e Sistemas Ambientais - INPE/CPTEC/DSA \\ E-mails:\{galante,machado\}@cptec.inpe.br
}

Recebido Novembro 2006 - Aceito Novembro 2007

\begin{abstract}
RESUMO
Este trabalho apresenta o desenvolvimento de um modelo para estimar a direção e velocidade do vento na baixa troposfera, com base no deslocamento de nuvens. O vento em baixos níveis é estimado a partir de um método automático, que utiliza como dados, as imagens dos canais visível e infravermelho próximo $(3,9 \mu \mathrm{m})$, ambos do satélite geoestacionário GOES-12. Para a estimativa do vento em baixos níveis, durante o período diurno, utilizou-se o canal visível e para o período noturno o canal infravermelho próximo. O alto contraste entre os albedos da superfície e o das áreas cobertas por nuvens, facilita a detecção das nuvens e o seu rastreamento durante o dia. Na detecção das nuvens baixas no período noturno, as imagens do canal infravermelho próximo mostraram-se mais eficazes do que as dos canais infravermelho janela e vapor d'água. Embora, sobre a região continental a aplicação do método tenha sido insatisfatória, devido à falta de homogeneidade das superfícies continentais, sobre os Oceanos foi possível estimar o vento com êxito. Este trabalho descreve em detalhes os métodos utilizados para determinar a altura dos vetores, o controle de qualidade e a validação feita com os dados do NCEP.
\end{abstract}

Palavras-Chave: vento, circulação atmosférica, satélites meteorológicos, nuvens.

\begin{abstract}
LOW-LEVEL WIND EXTRACTION FROM VISIBLE AND SHORTWAVE (3,9MM) INFRARED CHANNELS IMAGE DATA

This study presents the development and results of an automated tool for the estimation of lowertropospheric wind speed and direction based on cloud motion. This tool uses visible and near infrared $(3.9 \mu \mathrm{m})$ images from the geostationary GEOS-12 satellite. The visible band's high spatial resolution and contrast between low clouds and land surface were highly beneficial from tracking cloud motions. For nocturnal detection of low clouds, the near infrared channel performed better than both the infrared window and water vapor channels. The estimation of wind-related variables was obtained successfully over oceanic surface. However, over land, given surface heterogeneity, wind retrieval was not successful and only a few wind vectors were retrieved. The study presents the methodology used to assess cloud-base height, quality-control techniques, and validation whit NCEP data.
\end{abstract}

Keywords: wind, atmospheric circulation, meteorological satellites, clouds.

\section{INTRODUÇÃO}

Informações sobre a direção e velocidade do vento são de grande importância para inicialização dos modelos numéricos de previsão de tempo, análise sinótica da circulação atmosférica, estimativa de fluxos de massa e para o monitoramento da evolução de sistemas de nuvens. Podem ser medidas de diferentes formas, estações de superfície automáticas ou não, radiossondas, bóias oceânicas, navios e aviões são algumas delas. Contudo essas opções apresentam desvantagens no aspecto da resolução espacial e ou temporal. A utilização de imagens de satélites para estimar a direção e a velocidade do vento é uma opção muito interessante, comparada às formas citadas. A partir da determinação do deslocamento das nuvens presentes nessas imagens é possível determinar a direção e a velocidade do vento que provocou tal deslocamento, supondo-se 
que as nuvens se deslocam apenas devido à ação dos ventos. É possível estimar os ventos numa vasta região, já que a imagem do satélite geoestacionário representa uma área extensa do planeta.

O uso de imagens de satélites meteorológicos geoestacionários para estimar o vento a partir dos deslocamentos das nuvens, teve início no final da década de 60 e na primeira metade dos anos 70 (Fujita et al., 1969; Hubert e Whitney, 1971, Leese at al., 1971). Inicialmente, o rastreamento das nuvens era realizado manualmente e utilizava imagens dos canais infravermelhos. Com o passar dos anos e com o aumento do desempenho dos computadores, foram sendo desenvolvidos modelos automáticos de estimativa do vento. Imagens de diversas faixas do espectro infravermelho são utilizadas para este fim (e.g., Laurent, 1993; Homlund, 1993; Eigenwilling e Fischer, 1982). Imagens sucessivas na faixa do infravermelho possibilitam uma boa estimativa de vento nos níveis altos e médios, mas não são de grande utilidade para estimativa do vento nos níveis baixos, pois o contraste entre a temperatura do topo das nuvens baixas e os demais alvos na superfície é relativamente pequeno. Já nas imagens do canal visível, as nuvens baixas apresentam durante o período diurno, um forte contraste com relação à superfície oceânica. $\mathrm{O}$ albedo das nuvens é muito superior ao dos oceanos. Com isso, as variáveis relativas ao vento nos níveis baixos, podem ser estimadas em maior número e com maior precisão que os dados obtidos através dos canais infravermelhos termais (Laurent, 1993). O canal visível depende da presença da radiação solar, sendo inútil para o período noturno. Inicialmente, a utilização das imagens do canal visível se restringia aos estudos de caráter geral sobre tempestades tropicais (Rodgers et al., 1979). Na década de 90 essas imagens já eram utilizadas operacionalmente em modelos de estimativa das variáveis associadas ao vento (Andréas et al., 1996). Para estimar o vento em baixos níveis, durante o período noturno, o uso das imagens do canal infravermelho próximo $(3,9 \mu \mathrm{m})$ é uma boa opção, pois possibilita a detecção das nuvens baixas com mais precisão que o canal infravermelho (Thomas et al., 1997). O canal infravermelho próximo, além de operar na janela atmosférica, mostra características diferentes para nuvens altas (cirrus) e baixas, permitindo uma detecção mais precisa do vento em níveis baixos. Até o presente, foram realizados poucos estudos envolvendo o uso desse canal para estimar as variáveis associadas ao vento nos baixos níveis.

Com o passar dos anos, a estimativa do vento via satélites geoestaciónarios se tornou um produto importante, particularmente para a assimilação de dados para modelos de previsão numérica do tempo (e.g., Radford 1989; Thoss 1992). No Brasil, apenas o Centro de Previsão de Tempo e Estudos Climáticos (CPTEC) possui modelos de estimativa do vento a partir de imagens de satélites. Tais modelos utilizam imagens dos canais infravermelho janela (IVJ) $(10,7 \mu \mathrm{m})$ e do canal do vapor d'água $(6,7 \mu \mathrm{m})$, ambos do satélite GOES-12 e são eficientes na estimativa do vento para os níveis altos e médios, porém não são capazes de estimar com precisão os ventos nos níveis baixos. Laurent e Machado (1994), Machado et al. (1998), Laurent et al. (2002) descrevem os detalhes dos modelos em uso operacional no CPTEC.

O objetivo deste trabalho foi desenvolver um modelo utilizando os canais visível e infravermelho próximo para estimar os ventos nos baixos níveis com maior resolução espacial e com maior precisão que os modelos em operação no CPTEC.

\section{O MODELO DE ESTIMATIVA PARA OS BAIXOS NÍVEIS}

O modelo desenvolvido para a extração dos ventos na baixa troposfera é baseado no rastreamento das nuvens presentes nas imagens do canal 1 (banda visível, 0.55-0.75 $\mu \mathrm{m}$ com resolução espacial de $1 \times 1 \mathrm{~km}$ no ponto sub-satélite) e imagens do canal 2 (infravermelho próximo, $3,9 \mu \mathrm{m}$, com resolução de $4 \times 4 \mathrm{~km})$ do satélite geoestacionário GOES-12. As imagens do canal 1 são utilizadas para a extração de vento no período diurno e as imagens do canal 2 para o período noturno. A maior resolução espacial das imagens do canal visível faz com que estruturas menores sejam bem detectadas. Desta forma, seus deslocamentos são determinados com maior precisão e, conseqüentemente, a direção e a velocidade dos ventos que provocaram tais deslocamentos, também são estimadas com mais precisão.

As imagens utilizadas nesse modelo são recebidas operacionalmente no CPTEC. Essas imagens abrangem a América do Sul e parte dos oceanos adjacentes. Existem certas particularidades na utilização das imagens de cada canal devido ao tipo de informação contida em cada uma delas. Na imagem do canal visível, cada pixel representa uma medida do fator de reflectância de um dado local da superfície e nas imagens do canal infravermelho próximo $(3,9 \mu \mathrm{m})$, cada pixel está associado ao valor da temperatura de brilho (imagens noturnas) dos alvos que compõem a cena. Esta técnica utiliza o perfil de temperatura proveniente da análise do modelo regional ETA para auxiliar na estimativa da altura do vetor vento.

Entre os desafios vencidos no desenvolvimento deste trabalho podem-se citar a complexidade na estimativa da altura dos vetores, o controle de qualidade dos dados e a determinação das diferentes escalas espaciais de cômputo do vento.

\section{ESTIMATIVA DO VENTO}

A estimativa do vento a partir das imagens de satélite, baseia-se no rastreamento das nuvens presentes nessas 
imagens, determinando o seu deslocamento e deduzindo a direção e velocidade do vento. Parte-se da hipótese de que as modificações ocorridas nos campos de nuvens entre as duas imagens sucessivas se devem principalmente ao deslocamento provocado pelo campo de vento. Para esse rastreamento é utilizado um par de imagens de uma mesma região, América do Sul e oceanos adjacentes, por exemplo, com intervalo de tempo de 30 minutos. Na imagem no instante t0 são selecionadas áreas que contém estruturas de um campo de nuvem e a técnica se baseia em determinar a localização dessas estruturas na imagem subseqüente (no tempo t0+30min). As estruturas consistem em segmentos de imagem de $\mathrm{n} x \mathrm{n}$ pixels. A dimensão de tais segmentos está diretamente associada ao tipo de movimento que se deseja identificar, por exemplo, segmentos de grandes dimensões, em torno de $10.000 \mathrm{Km}^{2}$ tendem a captar movimentos de grande escala como o deslocamento de frentes e a circulação em regiões de baixa pressão. Vale ressaltar, que a resolução espacial das imagens influi na escolha da dimensão dos segmentos, limitando a utilização de segmentos de pequena dimensão em imagens de baixa resolução espacial.

Conhecendo a posição geográfica de cada estrutura em cada uma das imagens e o intervalo de tempo entre elas, é possível determinar a velocidade do vento que provocou o deslocamento das nuvens e também a sua direção, já que são conhecidas as posições inicial e final das estruturas. Porém, geralmente não é possível localizar uma estrutura idêntica na segunda imagem, pois as nuvens ou um conjunto delas modificam-se tanto pela ação dos ventos, quanto pelo seu próprio ciclo de vida. Dessa forma, o que se procura é a estrutura mais semelhante possível. Esse processo de rastreamento é automático, portanto a escolha das estruturas a serem rastreadas é feita de forma sistemática. Chamando de imagem 1, a imagem onde são selecionadas as nuvens a serem rastreadas, e de imagem 2, a imagem seguinte, o processo de rastreamento é realizado da seguinte forma: Determina-se na imagem 1 as subáreas denominadas janelas alvo, que contêm as estruturas a serem procuradas na imagem 2 . Uma sub-área é uma matriz quadrada de pixels obtida a partir da imagem 1. Determinada a janela alvo na imagem 1, procura-se a mesma estrutura (janela alvo) na imagem seguinte em uma região em torno da janela alvo na imagem 1. A avaliação da semelhança entre elas é feita a partir do cálculo da correlação entre as duas matrizes (janelas alvo). A direção e a velocidade do vento são obtidas a partir da localização geográfica do centro da janela 1 e da janela, na imagem 2, com a melhor correlação com a janela 1. A região de procura da estrutura de nuvens na imagem 2 é denominada janela de procura. Essa nova matriz tem a função de delimitar uma região onde serão procuradas as estruturas semelhantes, evitando que a busca seja feita por toda a imagem 2. A janela de procura é determinada em relação à dimensão da janela alvo de acordo com uma velocidade máxima esperada para um campo de nuvens baixas.

No processo de rastreamento utilizado, é necessário um conjunto de três imagens consecutivas, com intervalo de tempo de 30 minutos. A utilização de três imagens tem como objetivo realizar um teste de consistência temporal para cada vetor extraído. Esse teste visa avaliar a simetria entre um vetor extraído de um par de imagens no tempo t0 e t0+30 min e um outro par extraído no tempo t0-30min e t0. Esse teste é chamado de teste de simetria e será discutido em detalhes mais adiante.

Para zonas de convecção profunda, o período de maturação das nuvens é inferior a 30 minutos. Nesses casos a utilização de imagens com essa resolução temporal é inadequada, não sendo possível estimar o vento em baixos níveis. Porém é evidente, que em outras situações a aplicação dessas imagens é útil, como é mostrado nesse trabalho.

\section{CLASSIFICAÇÃO DAS NUVENS A SEREM RASTREADAS}

Visto que o modelo de extração de ventos a ser desenvolvido é para os níveis baixos, não havendo interesse de ventos nos níveis médios e altos, tem-se que as nuvens baixas devem ser identificadas e separadas das demais nuvens. É interessante que as nuvens médias e altas sejam eliminadas das imagens para não interferirem no cálculo das correlações, base do processo de rastreamento. O método utilizado para eliminar as nuvens altas e médias é substituir os pixels que representarem essas classes de nuvens por um valor aleatório inteiro pertencente aos intervalos $[200,324]$ e $[0,100]$ para as imagens do canal infravermelho próximo e visível, respectivamente. Observa-se que esse valor é tomado dentro do intervalo típico dos valores assumidos pelos pixels das imagens classificadas. Obviamente é necessário identificar primeiro que tipo de alvo cada pixel representa.

Para as imagens do canal visível, a classificação é feita utilizando um conjunto de parâmetros que definem as possíveis classes de nuvens e regiões de superfície que podem estar presentes numa imagem. Comparam-se os atributos de cada pixel com todos os parâmetros pré-definidos e aquele parâmetro correspondente à maior semelhança define a classe de nuvem (ou superfície) que o pixel avaliado representa. Já as imagens do canal infravermelho próximo são classificadas a partir de um limiar de temperatura de brilho. Além disso, a diferença entre a temperatura de brilho das imagens dos canais infravermelho próximo e IVJ permite identificar nuvens semitransparentes, que poderiam estar contidas no subconjunto de pixels selecionado pelo limiar escolhido. Esse método é baseado nos trabalhos de Stanley (2004) e Thomas et al. (1997).

\subsection{IMAGENS DO CANAL VISÍVEL}


Antes de iniciar o processo de rastreamento das estruturas utilizando imagens do canal visível é necessário realizar uma normalização dessas imagens. Essa correção é realizada para converter o fator de reflectância (F) de cada pixel num valor de reflectância (R). O fator de reflectância depende do ângulo de incidência da radiação solar. Tal conversão é realizada segundo a equação 1 .

$$
F=\frac{\pi L}{S} \quad R=\frac{h F}{\cos Z}
$$

Sendo L a radiância medida pelo sensor do satélite, $\mathrm{S}$ o fluxo especifico (relativo à faixa espectral observada) proveniente do Sol que incide sobre o topo da atmosfera, Z o angulo zenital solar e $\mathrm{h}$ o fator de correção da anisotropia da superfície refletora. Como o fator de anisotropia de cada nuvem é desconhecido optou por considerar as nuvens como isotrópicas, isto é, o valor de h igual a 1 , valor que representa a refletância lambertiana (Lubin e Weber, 1995). O erro associado a essa aproximação cresce a medida que o ângulo zenital solar aumenta, logo, o método não deve ser usado para os momentos próximos ao nascer e por do sol.

Para a classificação das nuvens das imagens do canal visível, utiliza-se uma outra imagem do IVJ $(10,7 \mu \mathrm{m})$ referente à mesma cena. Imagens do canal infravermelho auxiliam na classificação dos campos de nuvens, pois permitem caracterizar a estrutura espacial do topo e, em uma primeira aproximação, a altura do topo da nuvem. Vale ressaltar que essas imagens do canal IVJ apresentam resolução espacial menor que as imagens do canal visível utilizadas, sendo a resolução espacial de $4 \times 4 \mathrm{~km}$ no ponto sub-satélite. Devido às diferentes resoluções espaciais entre os dois tipos de imagens (visível/infravermelho), uma área representada por um pixel na imagem do infravermelho corresponde a uma área de 16 pixels na imagem do canal visível. Dessa forma, é necessário definir um processo que permita a comparação entre elas, associando cada pixel da imagem do canal visível a um pixel da imagem do canal infravermelho. A melhor forma encontrada foi associar cada pixel da imagem do canal 4 a 16 pixels distintos da imagem do canal 1 .

Essa metodologia de comparação entre os dois tipos distintos de imagens traz consigo a inconveniência de que, alguns pixels representando nuvens médias e ou altas continuem presentes na imagem mesmo após a classificação das nuvens e também que pixels representando nuvens baixas podem ser descartados. Isso ocorre porque nem sempre essas regiões de $4 \times 4$ pixels da imagem do canal visível irão conter pixels representando somente nuvens altas, médias ou baixas. Mesmo com essa desvantagem o método mostrou-se eficiente, pois testes de consistência entre os vetores, geralmente eliminam aqueles que resultaram do rastreamento de nuvens altas e médias, por outro lado, a eliminação de cenas contento nuvens baixas é minimizada pelo grande número de vetores extraídos por este método.

O princípio do método de classificação adotado, para os casos diurnos, baseia-se em definir padrões de nuvem que são caracterizados por uma série de atributos. Os atributos avaliados no método são o fator de reflectância no canal visível, a temperatura de brilho no canal IVJ e coeficiente de textura dos canais visível e infravermelho. O coeficiente de textura consiste da variância espacial dos pixels circunvizinhos ao pixel em questão. A textura Tex de um pixel $\mathrm{P}(\mathrm{c}, \mathrm{l})$, é definida por:

$$
\operatorname{Tex}_{n}\left(P_{c, l}\right)=\log \left(\operatorname{Var}\left(\operatorname{Pxl}_{n}(i, j)\right)\right) \quad \begin{gathered}
i \in[c-1, c+1] \\
j \in[l-1, l+1]
\end{gathered}
$$

em que:

$\operatorname{Pxl}_{n}(\mathrm{i}, \mathrm{j})$ : valor espectral (reflectância ou temperatura de brilho) no canal $n$.

Var: variância espacial dos pixels que compõe a matriz de ordem três.

Esse parâmetro de textura, utilizado no processo de classificação, visa diferenciar uma região com a presença de nuvens baixas esparsas de uma nuvem do tipo cirrus semitransparente entre outras situações similares. Sabe-se que numa região onde existam nuvens baixas esparsas há a presença da componente da radiação de onda longa emitida pela superfície que não é absorvida pelas nuvens, sendo medida pelo sensor do satélite. Dessa forma, o sinal referente a uma área onde existam nuvens baixas muito próximas umas das outras, formando quase uma única estrutura, será diferente de um campo onde as nuvens baixas que o formam estejam distantes entre si, apresentando locais onde a superfície esteja exposta. Sendo assim, essas regiões são diferentes tanto na componente da reflectância da radiação solar quanto na radiação de onda longa medida.

A definição do padrão de cada tipo de nuvem é feita através do cálculo da distância entre o ponto do espaço formado pelos quatro atributos enumerados acima e um conjunto de pontos (centróides) formados pelos mesmos atributos das situações pré-definidas.

Esse conjunto de situações (centróides) foi obtido utilizando um método estatístico e interativo conhecido por “agrupamento dinâmico" (Desbois et al., 1982), método esse utilizado por Bottino (2000) em seu trabalho sobre a estimativa da radiação solar a partir de satélites, em que era necessária a classificação do tipo de nuvens existentes na atmosfera. Esse conjunto de centróides é gerado operacionalmente no CPTEC, seguindo o método do agrupamento dinâmico utilizando imagens do satélite geoestacionário GOES 12. Vale ressaltar 
que esses parâmetros não são exatamente os mesmos para todos os horários do dia, pois o ângulo de incidência dos raios solares em relação às nuvens varia ao longo do dia. Como as nuvens em geral não são superfícies Lambertianas (isotrópica), ou seja, não refletem a radiação incidente com a mesma intensidade em todas as direções, o sinal medido pelo sensor do satélite varia na sua intensidade à medida que o ângulo de incidência dos raios solares varia.

\subsection{Imagens do Canal Infravermelho Próximo $(3,9 \mu \mathrm{m})$}

Para o período noturno, a classificação não dispõe do canal visível e, portanto, permite apenas distinguir as nuvens baixas dos demais alvos presentes nas cenas. Ela é feita a partir de um limiar de temperatura de brilho. Assim, todas as nuvens que apresentarem temperatura de brilho inferior a esse limiar serão descartadas, pois supõe-se que sejam nuvens médias ou altas. O limiar de temperatura de brilho utilizado foi de $270 \mathrm{~K}$. Esse limiar é razoável para realizar uma primeira separação entre nuvens baixas, altas e médias, pois espera-se uma certa absorção pelo vapor d'água da radiação emergente. Pixels com temperatura de brilho abaixo deste limiar, isto é, nuvens com topos mais frios que esse valor, são assumidos como representativos de campos de nuvens médias ou altas, sendo descartados das imagens. Buscando eliminar o problema da semi-transparência das nuvens, é calculada a diferença entre os canais 2 e 4 (infravermelho próximo, 3,9 $\mu \mathrm{m}$ e IVJ, $10,7 \mu \mathrm{m}$ respectivamente), do satélite GOES-12. De acordo com Thomas (2000), pixels cujos valores da diferença entre os canais são inferiores a $-3 \mathrm{~K}$ indicam a presença de nuvens cirrus, portanto, devem ser descartados. Essa diferença ocorre porque a transmissividade da nuvem cirrus no canal IVJ é maior que no canal infravermelho próximo. Após a classificação das nuvens, os pixels que não representam nuvens baixas são substituídos por um valor aleatório, desta forma, as correlações entre as diferentes cenas não são influenciadas pelos pixels que representam outros tipos de nuvens.

\section{CONTROLES DE QUALIDADE}

Em um modelo automático de estimativa do vento é necessário que os vetores estimados sejam avaliados, verificando se tais vetores descrevem o movimento de algum conjunto de nuvens ou trata-se apenas de um erro ocorrido durante o rastreamento dessas estruturas. O primeiro fator que determina a rejeição de um vetor é o valor da correlação calculada entre o par de segmentos de imagem durante o processo de rastreamento. Caso esse valor seja inferior a um determinado limiar o vetor é descartado. A escolha de tal limiar é determinante na quantidade de vetores que serão estimados e também na quantidade de vetores errôneos (ruído). Como o valor da correlação é um número $\mathrm{x}$ tal que $\mathrm{x} \leq|1|$, tem-se que limiares próximos de 1 fornecem vetores mais confiáveis porém a quantidade é reduzida. Por outro lado, limiares próximos de 0 fornecem uma quantidade maior de vetores mas muitos desses tratam-se apenas de ruído. Após uma série de experimentos utilizando vários coeficientes de correlação distintos, foram escolhidos os valores 0,7 e 0,5 quando utilizadas imagens dos canais visível e infravermelho próximo respectivamente. Devido a menor dimensão das janelas alvos utilizadas para o canal visível o limiar teve de ser escolhido mais próximo de 1. A quantidade de ruído é mais elevada a medida que o tamanho da janela diminui. Esses valores foram selecionados levando em consideração a relação entre vetores certamente errôneos (altos valores de velocidade) e o número total de vetores obtidos.

Um segundo teste, o teste da mínima porcentagem tem a finalidade de eliminar as cenas de rastreamento que não são representativas de um campo de nuvens baixas. Logo, cenas compostas por grande número de valores aleatórios foram descartadas. Sua finalidade é diminuir o nível de ruído e o tempo de processamento, já que é realizado no início do processo de rastreamento, logo após a escolha da janela alvo.

Outro teste aplicado é o teste de simetria, que consiste em verificar a consistência temporal entre cada par de vetores obtidos em diferentes tempos. Este teste é realizado entre os dois vetores extraídos entre as imagens no tempo t0-30min e a t0 e entre t0 e t0+30min. Espera-se que a evolução do movimento atmosférico no intervalo de 30 minutos não implique em grandes modificações, tais como mudanças muito bruscas na velocidade e na direção do vento. Esse processo de controle de qualidade é amplamente utilizado de forma similar nos modelos de extração de vento desenvolvidos em outros centros de previsão, como a agência européia EUMETSAT e o CPTEC. Esse teste é descrito em detalhes por Laurent et al., 2002 e Sakamoto e Laurent, 2003. Para verificar se os vetores são consistentes, ou seja, se não apresentam velocidade e direção muito diferentes entre si, é calculada a diferença vetorial entre tais vetores e o resultado do cálculo é avaliado pela equação 3. Caso a equação seja satisfeita o vetor é aceito pelo teste.

$$
\left|\overrightarrow{\mathrm{v}_{2}}-\overrightarrow{\mathrm{v}_{1}}\right|<\alpha_{s i m}+\left|\overrightarrow{\mathrm{v}_{2}}\right| \gamma_{s i m}
$$

$\mathrm{Na}$ equação acima, $\mathrm{V}_{1}$ e $\mathrm{V}_{2}$ são os vetores estimados entre os dois pares de imagens, $\alpha_{\text {sim }}$ indica um valor de referência da velocidade e $0<\gamma_{\text {sim }}<1$ determina um percentual da velocidade de $\mathrm{V}_{2}$. Outro teste aplicado é o teste de consistência espacial, este teste compara cada vetor com os vetores circunvizinhos contidos numa determinada área 
(Laurent et al., 2002). A intenção é eliminar vetores que não são homogêneos espacialmente, não descrevendo um campo coerente de movimento atmosférico na escala em que o vetor esta sendo extraído. Nessa comparação, a velocidade e a direção de cada vetor são avaliadas separadamente. Esse teste é aplicado somente se existir uma quantidade mínima de vetores numa dada área ao redor do vetor avaliado. A velocidade do vetor avaliado é comparada à média das velocidades dos $\mathrm{k}$ vetores mais próximos. A comparação é feita pela equação 4 e o vetor é rejeitado caso ela seja satisfeita.

$$
\alpha_{c e} V(x)>\frac{1}{k} \sum_{n=1}^{k} V(n)
$$

Em que V(x) é a velocidade do vetor avaliado e V(n) são as $n$ velocidades dos $n$ vetores próximos a $\mathrm{V}(\mathrm{x})$.

A constante $\alpha_{\text {ce }}$ é ajustada de forma a definir quanto a velocidade do vetor pode ser superior a média da velocidade dos vetores vizinhos. Essa etapa visa eliminar os vetores que possuem velocidade muito elevada em relação aos vetores próximos. Já a direção do vetor é avaliada calculando a diferença do vetor analisado em relação aos vetores mais próximos. A diferença entre cada vetor recebe um peso diferente baseada na distância do vetor em questão. Esse peso é ajustado pela função, $\mathrm{f}(\mathrm{x})=\mathrm{e}^{-\mathrm{qx}} \operatorname{com} \mathrm{q}=1,83$. $\mathrm{O}$ valor da constante $\mathrm{q}$ é ajustado empiricamente para que a função tenda a zero mais rapidamente e o teste apresente os melhores resultados. Dessa forma, tem-se que a contribuição de vetores cuja distancia seja maior que meio grau de latitude/longitude terá peso inferior a $40 \%$ na soma das diferenças. Esse teste consiste em verificar se a somatória das diferenças é inferior a um dado limiar, caso o seja, o vetor é aceito senão é rejeitado. A comparação é feita pela equação 5 :

$$
\alpha_{c e}>\frac{1}{k} \sum_{n=1}^{k} \operatorname{Dif}(n) \frac{1}{e^{q d_{n}}}
$$

Em que:

Dif(n): é o módulo da diferença vetorial entre o n-ésimo vetor mais próximo,

$\mathrm{d}_{\mathrm{n}}$ : distancia do n-ésimo vetor mais próximo, q: constante

A Figura 1 apresentada dois campos de ventos em baixos níveis referentes a um segmento extraído de uma imagem do dia 21 de setembro de 2004. À esquerda é apresentado o campo sem controle de qualidade, onde o único parâmetro utilizado para rejeitar ou não um vetor é o coeficiente de correlação e à direita é mostrado o mesmo campo, porém após a aplicação do teste de controle de qualidade. Torna-se evidente que a aplicação do controle de qualidade é importante para o processo de estimativa do vento a partir de imagens de satélites.
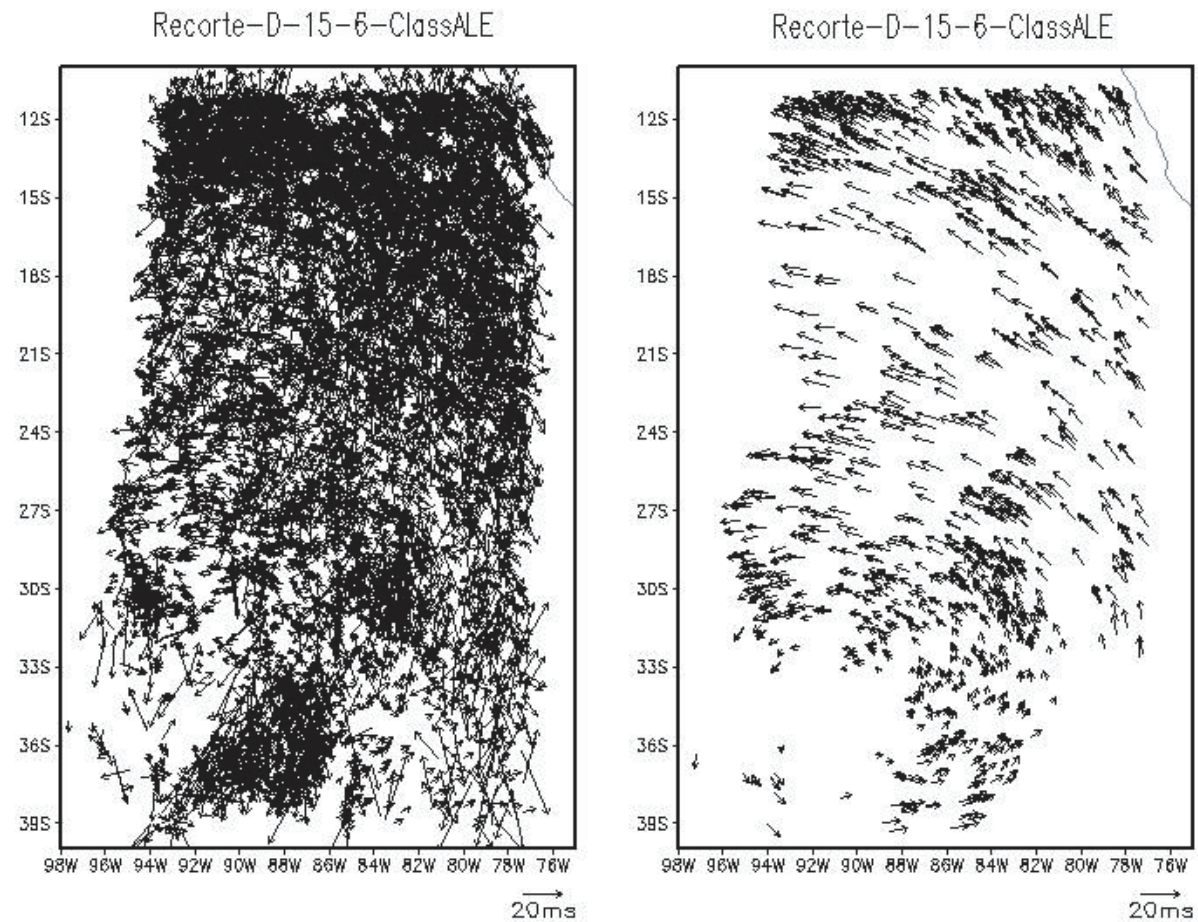

Figura 1 - Campos de vento resultantes sem a aplicação do controle de qualidade (esquerda) e com a aplicação de todos os testes do controle de qualidade (direita). 


\section{DETERMINAÇÃO DO NÍVEL DE PRESSÃO (ALTURA) DOS VETORES}

Segundo Smith e Hasler (1976) as nuvens baixas se deslocam em função do vento na altura da base da nuvem. Seguindo essa hipótese, a altura de cada vetor de vento estimado é tomada como sendo a altura da base do conjunto de nuvens utilizado em tal estimativa. A altura dos vetores é determinada a partir de uma técnica baseada no método proposto por Marshall et al. (1994) e Schmetz et al. (1996), que implica no cálculo de um histograma da temperatura de brilho do canal 4 para cada vetor. Esse histograma é calculado a partir do segmento de imagem (janela alvo) utilizado para estimar o vetor. Os histogramas são utilizados para estimar a temperatura de brilho da base das nuvens a partir de uma descrição do campo de temperatura de brilho da cena que contém informações dos topos das nuvens e da superfície. A conversão da temperatura estimada em um nível de pressão (altura) é feita com base em um perfil de temperatura da atmosfera (perfil proveniente do modelo ETA do CPTEC). A técnica baseia-se na hipótese de que os histogramas bi-modais descrevem duas populações distintas, uma da superfície e outra das nuvens. A intersecção destas duas populações refere-se à temperatura típica da base da população de nuvens baixas presente no segmento de imagem. De forma prática, um polinômio é ajustado a esse histograma e o ponto de mínimo local desse polinômio corresponde à temperatura de brilho da base da nuvem. O polinômio foi ajustado pelo método dos mínimos quadrados. A escolha do grau do polinômio $\mathrm{P}(\mathrm{n})$ foi feita empiricamente elegendo-se um valor que fornecesse uma aproximação satisfatória. A utilização de um polinômio de grau 12 permitiu que a precisão da aproximação fosse suficiente

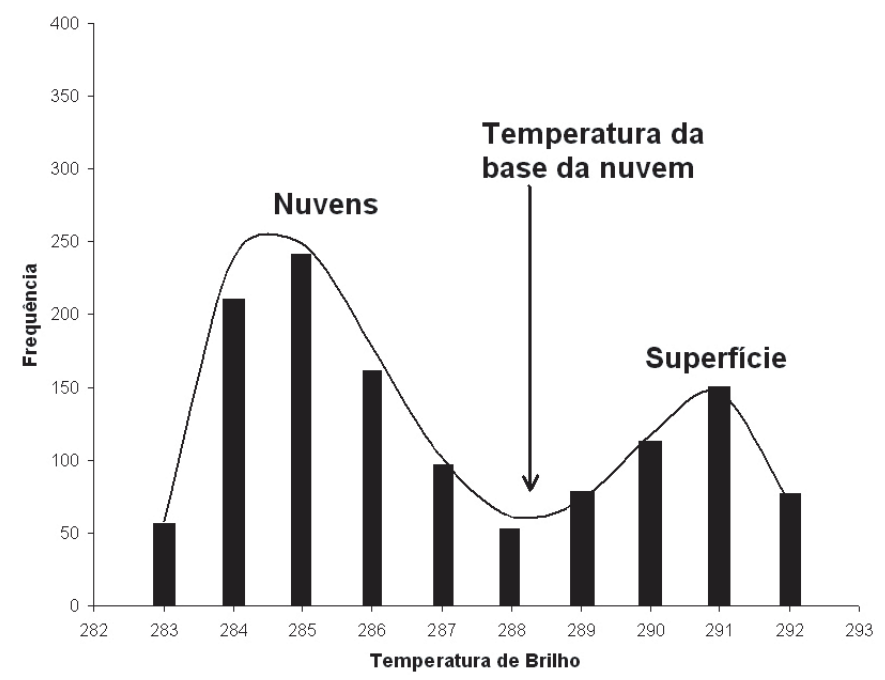

Figura 2 - Representação esquemática de um histograma típico para uma região oceânica com presença de nuvens baixas e áreas de céu claro. para a execução da técnica, descrevendo com facilidade a distribuição característica das duas populações de pixels (nuvens e superfície). O polinômio, ajustado ao histograma, possui a mesma função das duas gaussianas utilizadas pelo método descrito por Schmetz et al. (1996) usado para determinar a zona de transição entre céu encoberto e céu claro, ou seja, a altura da base das nuvens. Tal zona de transição é representada pelo mínimo entre as duas populações do histograma. O ponto de mínimo, que determina a temperatura de brilho da base da nuvem, encontra-se entre os dois máximos locais da função, como indicado na Figura 2. É necessário que o polinômio possua apenas um ponto de mínimo entre dois pontos de máximo no intervalo do histograma.

Foram testadas diversas dimensões de segmento para o cálculo da altura da base. Pequenos segmentos não contêm uma população de pixels suficiente para gerar um padrão semelhante ao mostrado na Figura 2. Observou-se que quanto maior a dimensão desse segmento mais definido é o histograma e, conseqüentemente melhor é o ajuste da curva polinomial. Contudo, áreas muito grandes poderiam não corresponder à altura efetiva da base das nuvens associadas ao vetor obtido. Logo, optou-se por escolher a menor janela com 16 x 16 pixels, que de um modo geral apresenta o histograma bimodal, até a área máxima de 100 x 100 pixels que corresponde a maior janela possível de procura do histograma. Adotou-se o seguinte critério para definir a dimensão do segmento: a partir de janelas de 16 x 16 pixels procura-se um polinômio cuja primeira derivada possuísse três raízes reais no intervalo do histograma ou atingisse um valor máximo, não ocorrendo essa janela é ampliada até que essa condição seja satisfeita ou até que a mesma seja maior que 100, neste caso o vetor é descartado, pois não pode-se calcular com precisão a altura do mesmo.

\subsection{Avaliação do Método de Determinação da Altura dos Vetores}

Em todos os campos deduzidos para a série utilizada, a quantidade de vetores determinada sobre as regiões continentais é desprezível. A maior parte dos vetores foi estimada sobre as regiões oceânicas, dificultando a validação do modelo. O uso de perfis atmosféricos provenientes de radiossondagens seria a forma mais indicada para avaliar os campos de vento resultantes. Não existem, no entanto, dados disponíveis sobre as regiões oceânicas onde a quantidade de vetores é maior e mais representativa. Assim, foi descartada a utilização de perfis atmosféricos feitos por radiossondas, utilizando nessa avaliação apenas os dados de re-análise fornecidos pelo NCEP (National Centers for Enviromental Prediction), dispostos numa grade regular de 2.5 × 2.5 graus, em 17 níveis de pressão e nos horários sinóticos Kalnay et. al., (1996). 
Inicialmente, verificamos a precisão do método de estimativa da altura base da nuvem. A forma encontrada para a realização deste teste foi através do cálculo do erro médio quadrático (RMS) dos vetores em relação aos campos fornecidos pelo NCEP, supondo que a altura determinada corretamente levaria ao menor erro. Os dados de vento do NCEP são fornecidos apenas nos níveis de 1000, 925, 850 e $700 \mathrm{hPa}$ para os níveis baixos. Já os vetores do campo estimados por este método podem assumir qualquer altura (nível de pressão) em qualquer valor no intervalo de 1000 a $700 \mathrm{hPa}$. Assim, durante o cálculo do RMS e do viés, os valores das componentes zonal e meridional dos campos do NCEP foram interpoladas de forma que a cada vetor do campo avaliado, correspondesse a um vetor referente ao campo do NCEP no mesmo nível de pressão. Devido à baixa resolução espacial dos campos do NCEP em relação à resolução do campo resultante do modelo, apenas os vetores que estivessem à distância máxima de 1 grau de um vetor do campo do NCEP foram utilizados na avaliação.

A Figura 3 mostra o valor do RMS calculado entre os vetores extraídos da série e os campos do NCEP. O valor da altura dos vetores foi subestimado e superestimado em intervalos de $25 \mathrm{hPa}$ a fim de verificar a qualidade das estimativas da altura do vetor vento.

Pelo gráfico apresentado na Figura 3A, nota-se que o menor valor do RMS ocorre quando a altura do vetor estimado é cerca de $25 \mathrm{hPa}$ maior que o valor dos campos obtidos pelo NCEP. Esse viés ocorre não em função do método empregado, mas quando utilizamos a hipótese de que a temperatura de brilho medida pelo satélite corresponde a temperatura do ar no mesmo nível. Devido à existência de vapor d'água acima do topo da nuvem, a radiação emergente é parcialmente absorvida e portanto a temperatura de brilho é levemente reduzida. Utilizando o modelo de transferência radiativa FLISS (Fomin, 1994) e um perfil climatológico das regiões tropical e extratropical, calculou-se a absorção da radiação de onda longa na janela atmosférica em $10,7 \mu \mathrm{m}$ do canal 4 do satélite GOES-12 opera. Devido a essa absorção, é esperado para a região tropical um decréscimo de cerca de 1,5 K. Para a região extratropical espera-se um decréscimo de cerca de $1 \mathrm{~K}$ na temperatura de brilho. Aplicando essa correção à temperatura estimada para a base da nuvem obteve-se um resultado mais consistente do que o anterior. A Figura 3B mostra que o valor do erro aumenta à medida que se subestima ou se superestima a altura (nível de pressão) da base das nuvens, confirmando que a estimativa para a base da nuvem utilizada torna-se melhor com essa correção, sendo bastante coerente com os dados do NCEP.

\section{AVALIAÇÃO GERAL DO MODELO}

Horários de transição entre o período noturno e diurno e vice-versa foram descartados, porque a contaminação da componente solar nas imagens do canal infravermelho próximo é intensa além do forte ângulo zenital solar, que intensifica os efeitos de isotropia das nuvens. Na análise do canal visível, deu-se preferência a horários contidos no intervalo de 10:00 a 20:00 UTC; para o canal infravermelho próximo, no intervalo de 22:00 a 08:00 UTC.

A série de campos de vento estimados no período de 21 a 25 de março de 2005 é composta por 9 campos do canal visível e 19 do canal infravermelho próximo. O número de campos

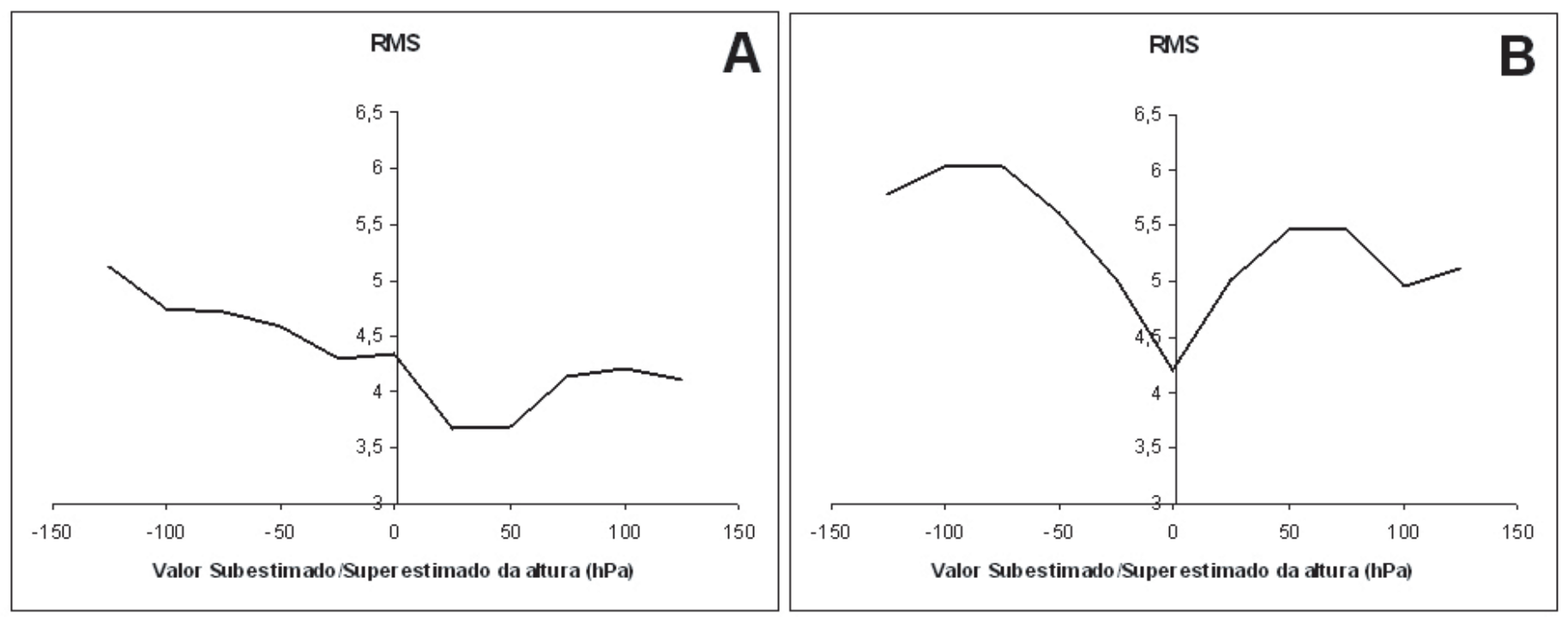

Figura 3 - (A) Erro quadrático médio do campo de vento em relação ao campo de vento calculado pelo NCEP em diferentes níveis. A ordenada corresponde à diferença na altura do vento entre os dois conjuntos de dados. (B) Erro para o caso em que foi aplicada a correção na temperatura de brilho, devido à absorção do vapor d'água presente nas camadas superiores ao alvo. 
para o canal visível foi menor devido à ausência de imagens para completar o trio necessário para o cômputo do vento. Em geral, a quantidade de vetores sobre o continente foi desprezível para os campos obtidos com a utilização do canal visível ou infravermelho próximo. Devido à ausência de radiossondagens nas regiões oceânicas, essa série de dados foi comparada aos campos de vento da re-análise do NCEP a partir do cálculo do erro quadrático médio (RMS) e do viés (bias) vetorial e da sua magnitude.

A Tabela 1 apresenta a comparação entre as estatísticas calculadas para o período de cinco dias em relação aos campos fornecidos pelo NCEP. Mostra também, as estatísticas realizadas no trabalho de Laurent et al., 2002 utilizando o modelo operacional do CPTEC, mas empregando o canal IVJ do satélite para estimar o vento em baixos níveis. Na primeira linha são mostrados os valores para toda a série (canal visível e infravermelho próximo), nas duas linhas seguintes estão os valores calculados individualmente para cada tipo de imagem utilizada (modelo para imagens do canal visível e imagens do canal infravermelho próximo). Por último, encontram-se os resultados referentes aos resultados apresentados por Laurent et al, (2004) para os baixos níveis usando o modelo operacional do CPTEC e o canal IVJ. Nesta tabela, Vis/IVP indica as estatísticas para todo o conjunto de campos. Vis indicam as estatísticas calculadas para os campos estimados a partir das imagens do canal visível e IVP aquelas calculadas para os campos estimados das imagens do canal infravermelho próximo. IVJ refere-se às estatísticas em relação trabalho de Laurent et al. (2004).

A título de comparação com os erros associados à estimativa do vento em baixos níveis por outras agências espaciais, a Tabela 2 apresenta uma comparação entre as estatísticas obtidas pelo modelo da EUMETSAT. Estas estatísticas se referem ao mês de setembro de 2004 para a área do disco de cobertura do satélite METEOSAT. Os campos estimados pela EUMETSAT, cuja estatística é apresentada na Tabela 2, foram obtidos a partir de imagens de um satélite

Tabela 1 - Avaliação dos campos de vento estimados para o período de 21 a 25 de março em relação aos campos do NCEP e a avaliação realizada por Laurent et al., (2002) para o modelo operacional da Divisão de Satélites e Sistemas Ambientais (DSA) do CPTEC. Vis - vento obtido pelo canal visível, IVP - vento obtido pelo canal infravermelho próximo e IVJ corresponde aos resultados de Laurent et al, (2004).

\begin{tabular}{|c|c|c|c|c|c|}
\hline & $\begin{array}{c}\text { RMS } \\
\text { Vetorial } \\
(\mathrm{m} / \mathrm{s})\end{array}$ & $\begin{array}{c}\text { RMS } \\
\text { da } \\
\text { Velocidade } \\
(\mathrm{m} / \mathrm{s})\end{array}$ & $\begin{array}{c}\text { Viés da } \\
\text { Velocidade } \\
(\mathrm{m} / \mathrm{s})\end{array}$ & $\begin{array}{c}\text { Diferença } \\
\text { Média da } \\
\text { Velocidade } \\
(\mathrm{m} / \mathrm{s})\end{array}$ & $\begin{array}{c}\mathrm{N}^{\circ} \\
\text { Amostras }\end{array}$ \\
\hline Vis/IVP & 4.9 & 3.7 & -0.28 & 0.66 & 13504 \\
\hline Vis & 4.7 & 3.7 & -0.11 & 0.43 & 6924 \\
\hline IVP & 5.1 & 3.7 & -0.42 & 0.89 & 6580 \\
\hline IVJ & 10.3 & 4.9 & 0.5 & 3.5 & 44 \\
\hline
\end{tabular}

Tabela 2 - Avaliação dos campos de vento estimados para o período de 21 a 25 de março de 2005, comparada às estatísticas dos campos da EUMETSAT. Vis - vento obtido pelo canal visível, IVP - vento obtido pelo canal infravermelho próximo.

\begin{tabular}{|c|c|c|c|}
\hline & $\begin{array}{c}\text { RMS Vetorial } \\
(\mathrm{m} / \mathrm{s})\end{array}$ & $\begin{array}{c}\text { Viés Vetorial } \\
(\mathrm{m} / \mathrm{s})\end{array}$ & $\mathrm{N}^{\circ}$ Amostras \\
\hline Vis & 4.7 & 0.11 & 6924 \\
\hline IVP & 5.1 & 0.42 & 6580 \\
\hline Vis Eumetsat & 3.6 & -1.31 & 22921 \\
\hline IVJ Eumetsat & 4.0 & -1.22 & 27283 \\
\hline
\end{tabular}

diferente (METEOSAT), pertencentes a outras regiões do planeta. Essa comparação mostra que o modelo de estimativa desenvolvido neste trabalho, apresenta uma capacidade de estimar o vento com erros similares à de um dos melhores modelos de estimativa de vento por satélite. É evidente que a utilização das imagens dos canais visível e infravermelho próximo, para estimar o vento em baixos níveis, proporciona melhores resultados que os outros canais disponíveis.

As Figuras 4 e 5 mostram dois campos de vento obtidos a partir deste processo. Observa-se, que devido a maior resolução espacial das imagens do canal visível, o nível de detalhamento do campo obtido é maior do que para o obtido com o infravermelho próximo. Na Figura 6 tem-se uma comparação entre um segmento do campo de vento estimado pelo modelo, baseado nas imagens do canal visível desse estudo e o modelo operacional da DSA que utiliza imagens do canal IVJ do mesmo satélite. A cena compreende parte do oceano Atlântico e a costa nordeste do Brasil. Observa-se que o campo de vento é muito mais detalhando para os baixos níveis, utilizando imagens do canal visível. Fica claro que a aplicação dessas imagens na estimativa do vento para os baixos níveis é uma ótima alternativa em relação às imagens do canal IVJ. A Figura 7 apresenta uma comparação similar entre um campo estimado utilizando o canal IVP, e um campo estimado pelo modelo operacional baseado no canal IVJ para a mesma cena. Também, pode-se verificar que as imagens do canal IVP proporcionam um campo mais consistente para os baixos níveis.

A estimativa do vento para latitudes maiores que $50^{\circ} \mathrm{S}$ não era possível, pois a área de abrangência das imagens do satélite GOES-12 utilizadas no trabalho compreendiam latitudes entre $30^{\circ} \mathrm{N}$ e $50^{\circ} \mathrm{S}$ e longitudes no intervalo de $-120^{\circ} \mathrm{W}$ a $-10^{\circ} \mathrm{W}$. A partir de 1 março de 2007 houve uma alteração na posição do satélite GOES-10, o qual passou a ser dedicado ao monitoramento de toda a América do Sul. Aárea de abrangência das imagens foi alterada em relação às imagens do satélite GOES-12, compreendendo latitudes entre $15^{\circ} \mathrm{N}$ e $90^{\circ} \mathrm{S}$. Isso tornou possível avaliar o modelo para essas regiões. Contudo, para latitudes abaixo de $50^{\circ} \mathrm{S}$ a resolução espacial dos pixels 
torna-se muito pobre. Com o ângulo de visada se aproximando de $90^{\circ}$ o sensor do satélite passa a "observar" as laterais das nuvens e não seus topos. Esse erro tende a aumentar a área coberta por nuvens nessas regiões e prejudica a identificação de padrões em imagens consecutivas, base do processo de rastreamento, diminuindo drasticamente a quantidade de vetores estimados para esses locais. Pode-se observar nas Figuras 4 e 5 , que a quantidade de vetores para latitudes inferiores a $50^{\circ} \mathrm{S}$ é praticamente inexistente. Vale ressaltar que os satélites GOES10 e GOES-12 possuem os mesmos canais utilizados nesse trabalho logo, as imagens possuem as mesmas características. Embora a resolução temporal das imagens do satélite GOES10 seja de 15 minutos, os exemplos apresentados utilizaram imagens com intervalo de 30 minutos.

\section{CONCLUSÕES E CONSIDERAÇÕES FINAIS}

Esse trabalho teve como objetivo desenvolver dois modelos para estimar o vento em baixos níveis a partir do deslocamento das nuvens presentes em imagens de satélites. Os modelos apresentados foram desenvolvidos a partir dos modelos que estavam em operação no CPTEC/DSA em 2005. Pelo fato de utilizarem imagens de canais diferentes e de visarem a estimativa do vento em baixos níveis, os novos modelos tiveram que ser adaptados significativamente. Diversas novas rotinas e processos foram desenvolvidos, principalmente no que se refere à classificação de nuvens, testes de controle de qualidade, combinação de diferentes canais e determinação de altura do vetor. O procedimento de classificação das nuvens foi introduzido com o intuito de eliminar nuvens médias e altas, evitando que influenciassem no processo de rastreamento. Classificando as nuvens presentes nas imagens, foi possível desconsiderar os pixels referentes a nuvens médias e altas aumentando significativamente a qualidade dos campos obtidos, evitando que o vento nas camadas atmosféricas médias e altas introduza erros no cálculo do campo de vento em baixos níveis. Em relação aos testes aplicados aos vetores para o controle de qualidade, parte foi desenvolvida exclusivamente nesse trabalho e os testes baseados nos modelos operacionais do CPTEC tiveram que ser modificados e adaptados. O teste de consistência espacial dos vetores, por exemplo, foi elaborado de forma a considerar separadamente a velocidade e direção dos vetores, diferentemente daquele que o originou, avaliando cada vetor do campo de vento em relação aos vetores em uma determinada vizinhança. Esse novo teste se mostrou bastante eficiente e permitiu eliminar uma grande quantidade de vetores errôneos sem que fosse retirada uma grande quantidade de vetores corretos. Como resultados podem-se citar:

Os campos de vento obtidos nesse trabalho, para nuvens baixas, foram muito mais satisfatórios em número e qualidade, do que os obtidos com o canal infravermelho, o qual é utilizado em um modelo de estimativa do vento atualmente operacional no CPTEC.

O desempenho dos modelos foi considerável sobre as regiões oceânicas porém, não foram capazes de efetuar com a mesma eficiência a estimativa na região continental. Sobre os oceanos as modificações sofridas pelos campos de nuvens no intervalo de tempo de 30 minutos, geralmente não são tão expressivas como as modificações sobre o continente, se associando mais ao campo de vento do que a fatores locais como, por exemplo, à orografia. Esses fatores são consideravelmente importantes, uma vez que o modelo tem por hipótese que as modificações no campo de nuvem ocorrem principalmente devido à advecção pelo vento na base da nuvem. A grande maioria dos métodos encontrados na literatura para nuvens baixas é aplicada somente sobre os Oceanos.

As imagens dos canais visível e infravermelho próximo são mais indicadas que os canais IVJ $(10,7 \mu \mathrm{m})$ e vapor d'água $(6,5 \mu \mathrm{m})$ para estimar o vento em baixos níveis. O canal vapor d'água localiza-se em uma banda de forte absorção atmosférica, não permitindo destacar as propriedades da superfície. Já o canal infravermelho apresenta um pequeno contraste entre nuvens baixas e superfície, em função da proximidade entre as temperaturas de emissão.

O canal visível foi utilizado explorando sua alta resolução espacial com o intuito de obter um campo de vento altamente detalhado e preciso. O canal infravermelho próximo foi utilizado na estimativa do vento durante a noite, pois apresenta maior sensibilidade a temperaturas mais quentes, permitindo uma melhor detecção das nuvens baixas e, em função da diferente emissividade das nuvens, diferenciar cirrus finos de cumulus.

Desenvolvimento da técnica automática de estimativa da altura da base das nuvens utilizada para determinar o nível de pressão dos vetores estimados. Determiná-lo é tão importante, quanto determinar a direção e a velocidade do vento, pois o vento sofre alterações significativas com a altura. Os resultados provenientes deste método automático foram de muito boa qualidade. Um pequeno ajuste foi necessário para corrigir a absorção da radiação pelo vapor d'água acima do topo das nuvens.

A avaliação da precisão dos modelos desenvolvidos precisa ser expandida para uma série temporal maior que os cinco dias utilizados para possibilitar uma análise mais detalhada dos modelos. É importante a realização de um estudo que avalie o impacto da utilização dos campos de vento estimados a partir de satélites na inicialização dos modelos de previsão de tempo. Os campos estimados localmente contam com ajustes regionais, maior resolução espacial, temporal e menor tempo de latência. 


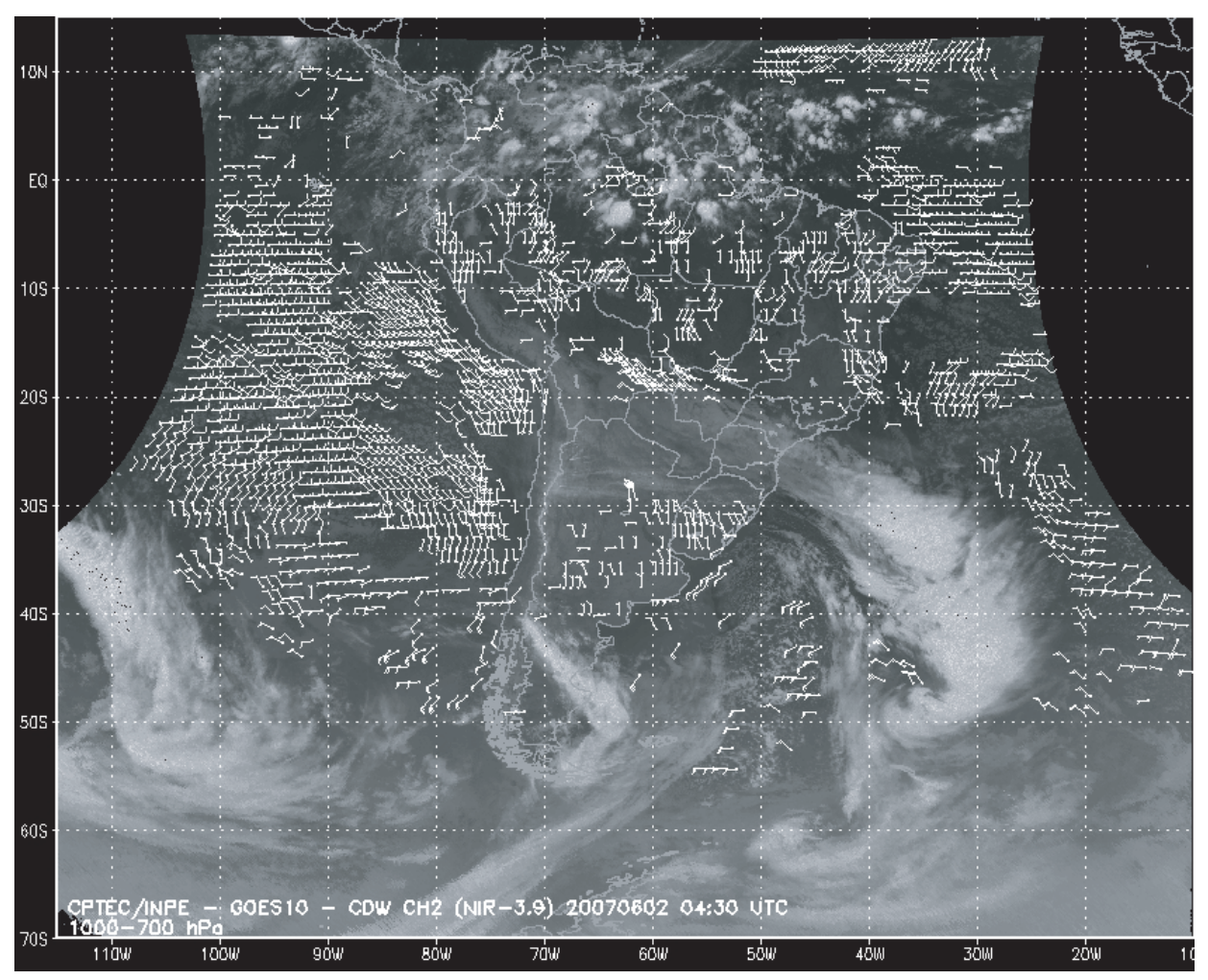

Figura 4 - Campo de vento, em baixos níveis, estimado pelo modelo baseado nas imagens do canal infravermelho próximo (3,9 $\mu$ m) referente ao dia 02 de maio de 2007, 0430 UTC.

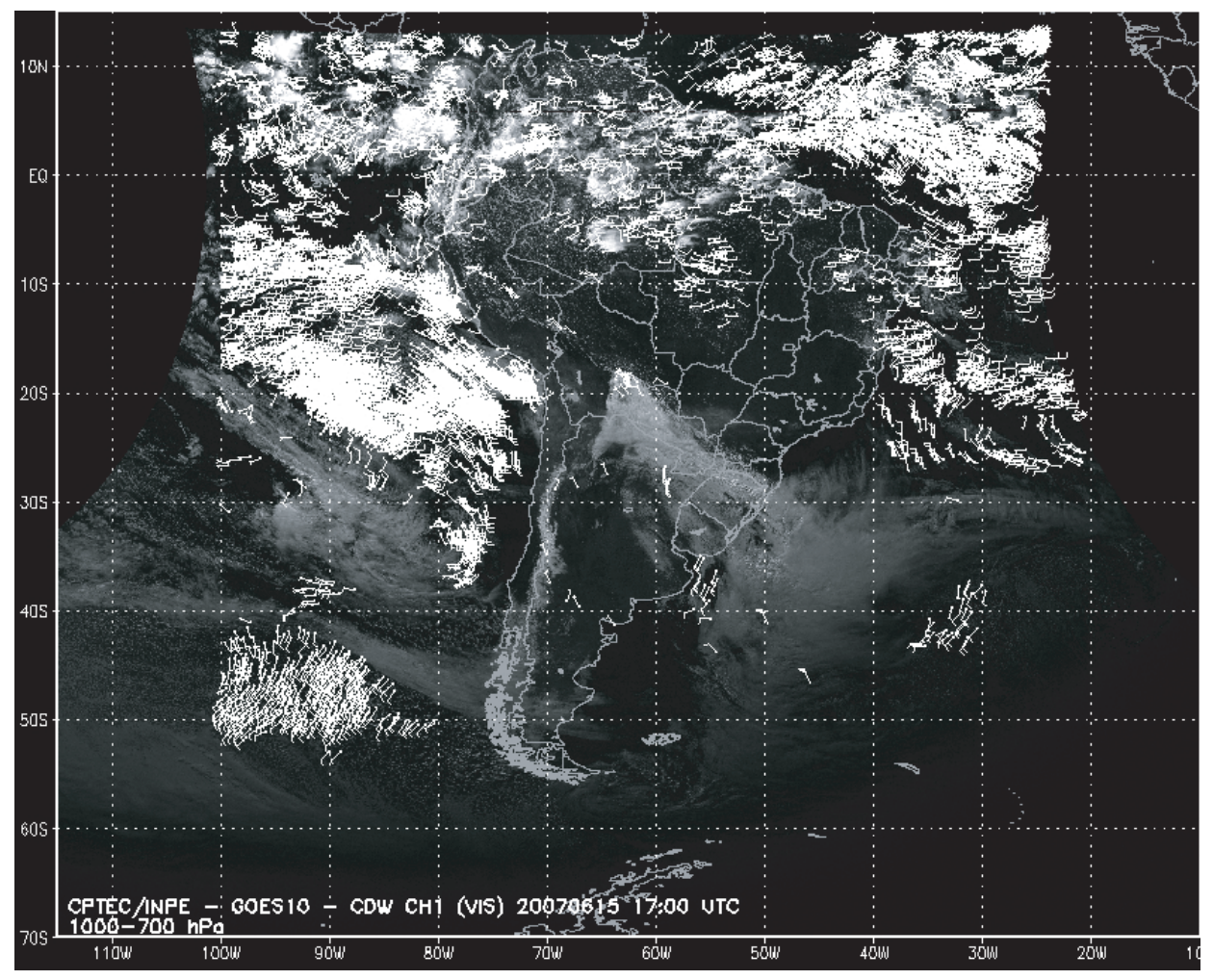

FIGURA 5 - Campo de vento, em baixos níveis, estimado pelo modelo baseado nas imagens do canal visível para o dia 15 de maio de 2007,1700 UTC. 


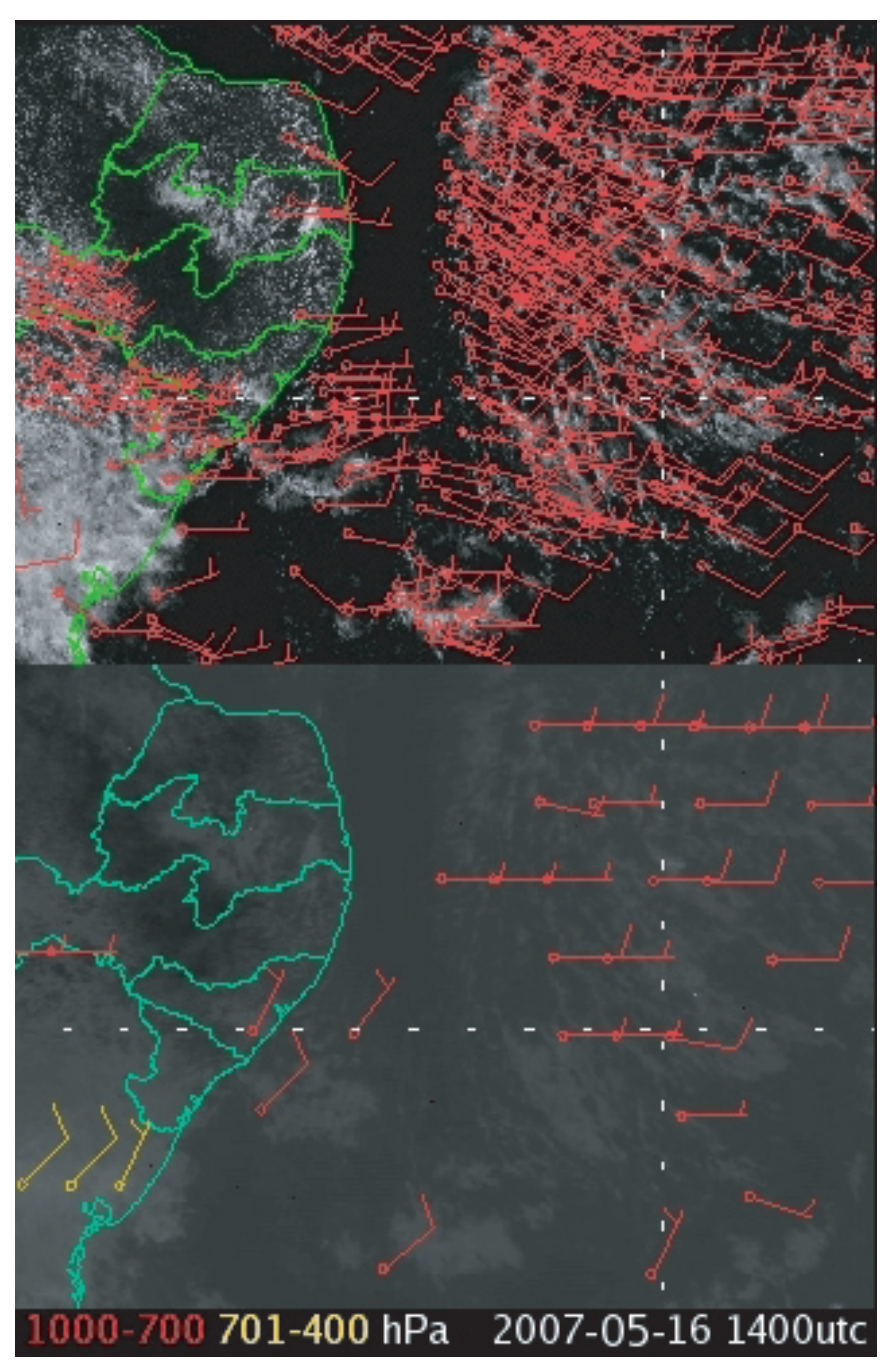

Figura 6 - Comparação entre o campo de vento estimado a partir das imagens do canal visível (acima) e IVJ (abaixo) para a mesma cena.

\section{REFERÊNCIAS BIBLIOGRÁFICAS}

ANDREAS, O. et al. Low-Level Cloud Motion Winds from METEOSAT High-Resolution Visible Imagery. Weather and Forecasting, v.12, p.175-184, 1997.

BOTTINO, M.J. Um Modelo de Estimativa de Radiação Solar Por Satélite: Análise e Aprimoramentos. 2000. 105p. Dissertação (Mestrado em Meteorologia) - Instituto Nacional de Pesquisas Espaciais, São José dos Campos, 2000.

DESBOIS, M. G.; SÈZE, E G.; SZEJWACH. Automatic Classification of Clouds on METEOSAT Imagery: Application to High-Level Clouds. Journal of Applied Meteorology, v.21, p.401-412, 1982.

EIGENWILLIN, N.; FISCHER, H. Determination of Midtroposferic Wind Vectors by Tracking Pure Water Vapor

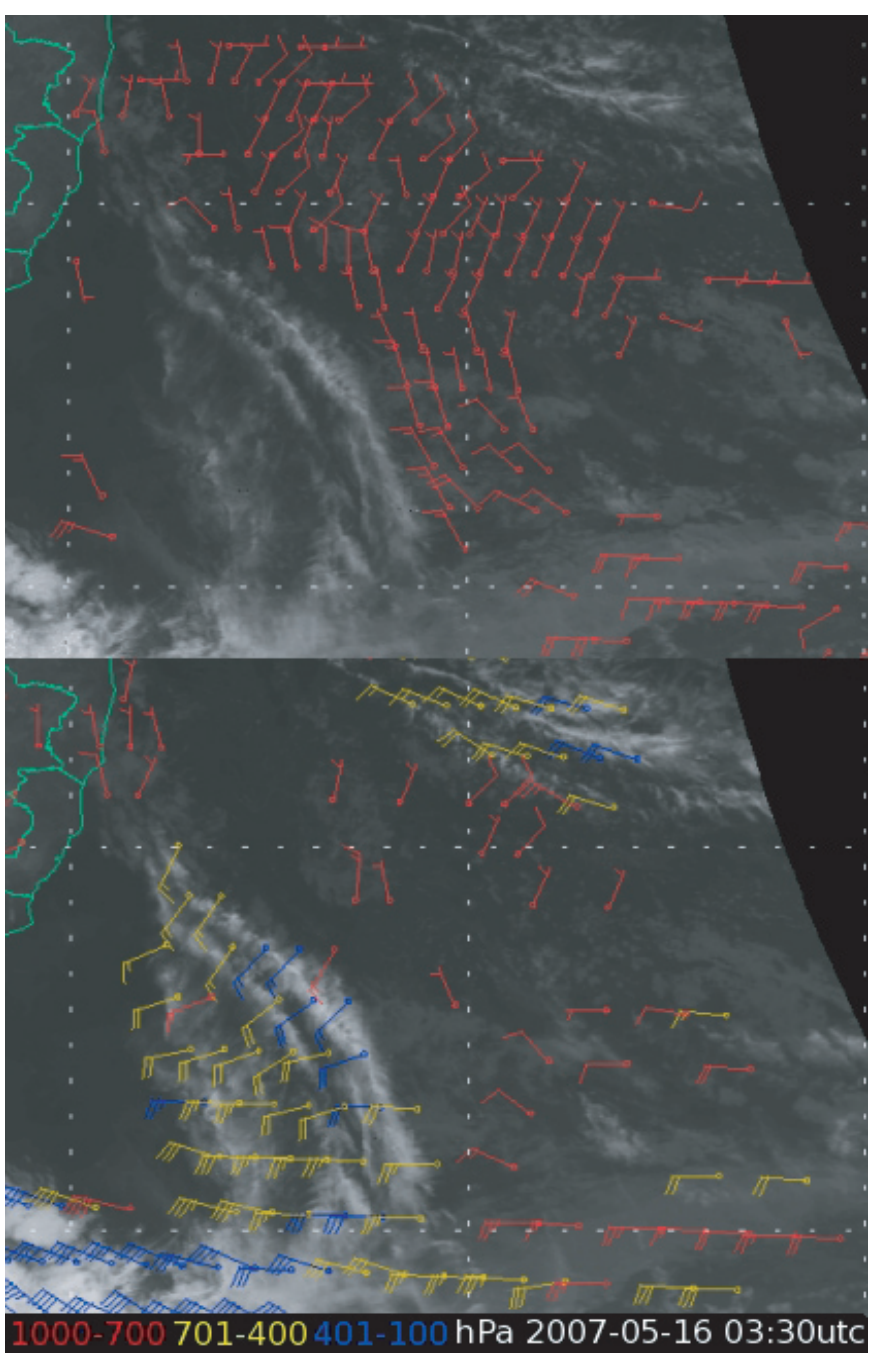

Figura 7 - Comparação entre o campo de vento estimado a partir das imagens do canal IVP (acima) e IVJ (abaixo) para a mesma cena.

Strucutures In METEOSAT Water Vapor Image Sequences. Bulletin of the American Meteorology Society., v.63, p.4458, 1982.

FOMIN, B.A. Benchmark, 1994: Computation for Solar Fluxes and Influxes in Aerosol and Cloudy Atmosphere. Izvetyia Atmospheric Oceanic Physics, V. 30, N. 3, P. 283-290.

FUJITA, T. T.; WATANABE K.; IZAWA T. Formation and Structure of Equatorial Anticyclones Caused By Large-Scale Cross-Equatorial Flows, Derived By Ats-1 Photographs. Journal of Applied Meteorology, v.8, p.649-667, 1969.

HOLMLUND, K. Operational Water Vapour Wind Vectors from METEOSAT Imagery Data. In: International Wind Workshop 2., 1993, Tokyo, Japan. Anais... 1993. p.77-84.

HUBERT, L. F.; WHITNEY, L. F. Jr. Wind GeostationarySatellite Pictures. Monthly Weather Review, v.99, n.9, p.665-671, 1971. 
KALNAY, E. et al. The NCEP/NCAR 40-year reanalysis project. Bulletin of the American Meteorological Society, Boston, v.77, n.3, p.437-471, 1996.

KIDDER, S. Q.; HAAR, T. H. V., 1995 Satellite Meteorology: An Introduction. San Diego: Academic Press, $1^{\text {a }}$ Ed., 1995. $466 \mathrm{p}$.

LAURENT, H. Wind Extraction from METEOSAT Water Vapor Channel Image Data. Journal of Applied Meteorology. v.32, p.1124-1133, 1993.

LAURENT, H.; MACHADO, L. A. T. Extração do Vento Utilizando Imagens de Satélites Meteorológicos. In: Congresso Brasileiro de Meteorologia 8, 1994. Belo Horizonte - MG. Anais... 1994.

LAURENT, H. et al. A. Extração do Vento Utilizando Imagens de Satélite no CPTEC: Nova Versão e Avaliação com Dados do WETAMC/LBA e dados Operacionais da DSA/CPTEC. In: International Winds Workshop 6., 2002. Madison, USA Anais... 2002. 1 CD-ROM.

LEESE, J. A.; NOVAK, C. S.; CLARK, B. B., 1971, An Automatic Technique for Obtaining Cloud Motion from Geostationary Satellite Data Using Cross Correlation. Journal of Applied Meteorology, 10, 118-132.

LUBIN D.; WEBER P, 1995. the Use of Cloud Reflectance Functions With Satellite Data for Surface Radiation Budget Estimation. Journal of Applied Meteorology, 34, 13331347.

MACHADO, L. A. T., et al. Extração do Vento e Estimativa de Sistemas Convectivos Utilizando Imagens do Satélite GOES. In: Congresso Brasileiro de Meteorologia 10, 1998. Brasília - DF. Anais... 1998.

MARSHALL, J. L., et al. An Operational System for Generating Drift Winds in the Australian Region and Their Impact on Numerical Weather Prediction. Weather and Forecasting,v.9, p.361-370, 1994.
RADFORD, A. Monitoring of Cloud-Motion Winds at ECMWF. Proc. ECMWF/EUMETSAT Workshop: the Use of Satellite Data In Operational Numerical Weather Prediction: 19891993, v.2, p.249-262, 1989.

RODGERS, E., et al. The Benefits of Using Short Interval Satellite Images to Derive Winds for Tropical Cyclones. Monthly Weather Review, v.107, p.575-584, 1979.

SAKAMOTO, M.; LAURENT, H. Wind Estimation - The Studies Made at Funceme. In: The 2003 EUMETSAT Meteorological Satellite Conference, Weimar, Germany, 29 September - 3 October 2003. Publ. EUMETSAT, In Press, p.3-15, 2003.

SCHMETZ, J.; HOLMLUND, K.; OTTENBACHER, A. Low-Level Winds from High-Resolution Visible Imagery. In: International Winds Workshop 3, Ascona, Switzerland, 1996. Anais... p.71-79, 1996.

SMITH, C. L.; HASLER, A. F., 1976: A Comparison of LowCloud Satellite Wind Estimates Whit Analyses Based on Aircraft Observations in a Disturbed Tropical Regime. Monthly Weather Review, 104, 702-708.

STANLEY, Q. K. Cirrus Detection and Characterization Using GOES 3.9 $\mu \mathrm{m}$ Albedo. Cira/Colorado State University, Fort Collins, Colorado. p.1-19, 2004.

THOMAS, F. L.; JOSEPH T.; RICHARDSON K. Stratus and Fog Products Using GOES-8-9 3.9- $\mu \mathrm{m}$ Data. Weather and Forecasting, v.12, p.664-667, 1997.

THOMAS, F. L. Nighttime Observation of Sheared Tropical Cyclones Using GOES 3.9 $\mu \mathrm{m}$ Data. Weather and Forecasting, notes and correspondence, p.759-766, 2000.

THOSS, A. Cloud Motion Winds, Validation and Impact in Numerical Weather Forecast. Proc. Workshop on Wind Extraction from Operational Meteorological Satellite Data, Washington, DC, EUMETSAT, p.105-11 